\title{
Chapter 3 \\ The Production Logistic Theory \\ as an Integral Part of a Theory \\ of Production Technology
}

\author{
Julian Becker and Peter Nyhuis
}

\begin{abstract}
He who loves practice without theory is like the sailor who boards ship without a rudder and compass and never knows where he may cast.
\end{abstract}

(Leonardo Davinci 1452-1519)

\subsection{Motivation}

Today's manufacturing companies operate in a turbulent environment. Globalisation, increasing market dynamism and ever shortening product life cycles are just some of the aspects that characterise the steady rise in competitive pressure (Roland Berger Strategy Consultants GmbH 2012; Abele and Reinhart 2011; Sirkin et al. 2004). Moreover, factors such as sustainability and the conservation of natural resources are playing an increasingly important role (BMU 2012; Deutsche Post AG 2010). In order to maintain sustainable production in a turbulent environment, it is necessary to be able to anticipate impending changes and to determine and assess available alternative courses of action. The determination of potential action strategies requires knowledge of how production facilities behave at all levels, including those of production networks, machines and processes. Accordingly, in order to maintain their long-term success, companies must be able to predict, analyse and influence changes and the impacts they have on their production. What this requires is a comprehensive theory by which to achieve a scientific understanding and an integral description of production technology. The development of a production logistic theory serves to clearly illustrate both the scientific and the practical benefits of such generally applicable theories. Using the example of production logistic theory, this article seeks to determine the fundamental requirements and challenges that are involved in developing such a theory and

J. Becker · P. Nyhuis $(\square)$

Hannover Centre for Production Technology (PZH), Institute of Production Systems and Logistics (IFA), An der Universität 2, 30823 Garbsen, Germany

e-mail: nyhuis@ifa.uni-hannover.de

(C) The Author(s) 2015

C. Brecher (ed.), Advances in Production Technology,

Lecture Notes in Production Engineering, DOI 10.1007/978-3-319-12304-2_3 
discusses the necessity of a model-based, holistic description of production. Initial approaches towards a theory of production technology are then indicated and future fields of development identified.

\subsection{Theory Development in the Context of Production Technology}

The interpretation of the term 'theory' may incorporate different aspects, depending on the scientific-theoretical viewpoint adopted, for which reason a brief definition will first of all be given here. The National Academy of Science in the USA defines a theory as "a well substantiated explanation of some aspect of the natural world that can incorporate facts, laws, inferences, and tested hypotheses" (National Academy of Sciences 1998, p. 5). Hence, theories constitute models of reality, on the basis of which it may be possible to derive recommended courses of action. They are verifiable through observation and remain valid until such time as they are scientifically disproven (Popper 1935).

In the context of production technology, theories play a role in generating knowledge, applying them and disseminating them. They are also used in developing production systems as well as in staff training activities. Interest groups include both scientists and users/operators as well as those in training and further education. An unambiguous definition of input, output and system parameters simplifies the basic understanding of the system. Moreover, the theory supplies explanatory models of system behaviour, and the use of uniform terminology enables communication within and between the various interest groups. When designing systems, the use of theory-based construction rules ensures that the required functions are fulfilled. In ongoing operation, theories support the enhancement of subsystems, as they also do in the coordination of subsystems among each other. This makes it possible to counteract, for instance, an obstruction, uncontrolled vibration or incorrect behaviour in a system. In a seminar situation, theories often serve to illuminate a body of knowledge gained through experience, while supplying explanations of system operation and enabling analysis of technical and logistic systems (Wiendahl et al. 2010; Nyhuis and Wiendahl 2007).

The development of a theory involves passing through several consecutive stages (Fig. 3.1). The first stage of theory formation comprises defining the scope of observation and laying down the content boundaries. It is then possible to derive research questions based on this foundation. After collecting together the necessary materials and available knowledge, models and submodels can be developed and validated by means of experiment and protocol. In turn, the hypotheses thus derived enable laws or partial laws to be defined. The combination of the models and laws thus developed ultimately leads to the formulation of (sub)theories of the scope of observation defined at the outset. The models, laws and hence the overall theory 
Fig. 3.1 Development of a theory

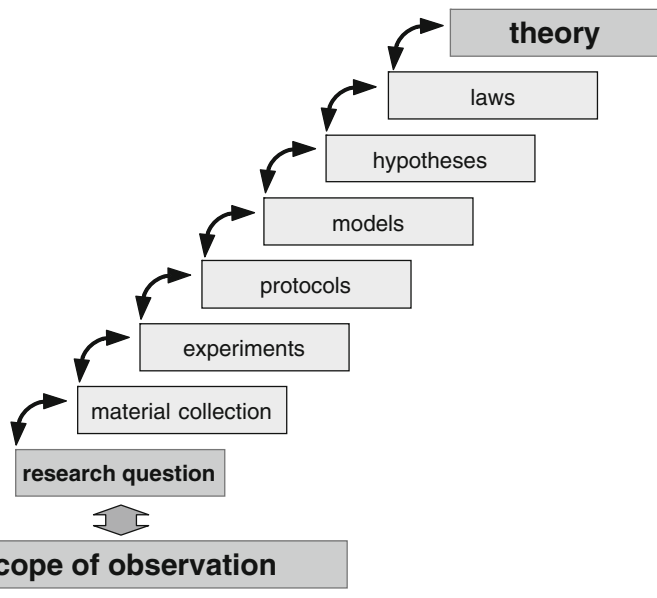

retain their validity until such time as they are scientifically disproven (Nyhuis and Wiendahl 2010).

Model development represents an essential tool in the generation of new knowledge and theories. A number of approaches can be taken in pursuing this end; these are illustrated in Fig. 3.2.

The experimental method involves gaining knowledge by empirical means such as observation and/or experiment. Another approach is to employ the deductive method, in which conclusions are drawn on the basis of purely logical interrelations. The knowledge gained by this means must be empirically verifiable in order for it to be of practical and scientific value. The experimental model frequently only describes a simulation or laboratory experiment for a very specific condition of a

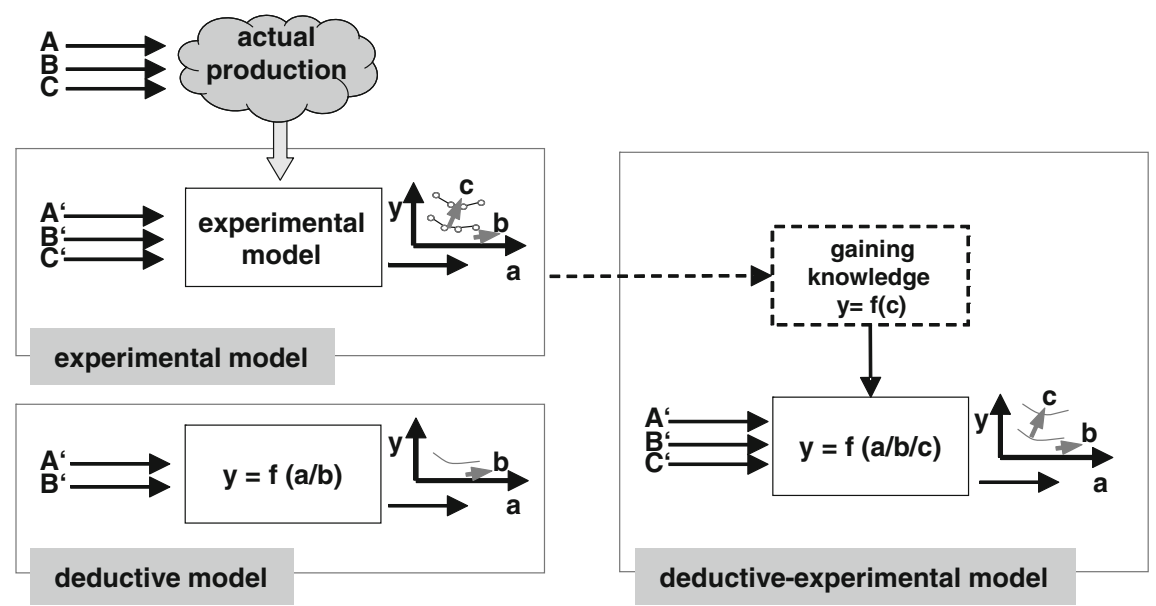

Fig. 3.2 Alternative approaches to developing a model 
simulation and the deductive model is often too abstract for the practically oriented user; however, the deductive-experimental model combines the respective advantages of both models. As far as it is not possible to produce a purely deductive model, it is primarily recommended that a deductive-experimental approach be taken and a deductively derived model substantiated by experimentation (Nyhuis et al. 2009).

This approach is the one primarily followed in the development of a theory of production logistics and is explained in detail in the following.

\subsection{Production Logistic Theory}

Weber (2008) remarked that a logistic theory could not be developed, since logistic questions were broadly distributed throughout the entire value chain. In the supply chain logistics activities are performed by different agents in the various organisational divisions, such as the purchasing, production and distribution departments. A further problem is frequently encountered by virtue of the differences in the target systems in the various divisions. This is precisely why it is urgently necessary to develop a logistic theory that makes it possible to orient the formation of the value chain and the activities of the agents towards a common goal.

The Institute of Production Systems and Logistics (IFA) has been studying the development of a comprehensive production logistic theory for the internal supply chain for more than 40 years. For this purpose, numerous research questions have been identified and logistic models developed that have been validated in practice and are in broad use. By linking the models, it is possible to conduct a model-based calculation of realisable logistics performance for virtually any configuration within the internal supply chain. Furthermore, basic laws of production logistics and other fundamental laws can be derived (these are however beyond the scope of the present article. Interested readers may obtain further information by referring to Nyhuis et al. (2009) and Lödding (2013)).

The so-called logistic operating curves are one of the best-known logistic models in scientific and practical use (Nyhuis 1991, 2007). The aim of this chapter is to show by example how to develop a model successfully and what challenges exist.

The aim of a logistic operating curve is to show a mathematical relationship between the determining factor work in process and the resulting target variables output rate and range of a workstation. Moreover, all relevant framework conditions and real determining factors that impact on the workstation must be taken into consideration (Fig. 3.3). The basis of the model is the throughput diagram, which shows the throughput with respect to time (Wiendahl 1987; Kettner and Bechte 1976; Heinemeyer 1974). The work content entering the workstation is shown in the form of an input curve while the throughput is shown cumulatively over time as an output curve. By presenting the information in this way, it is possible to describe the system's behaviour in terms of the logistic parameters of work in process, output rate and range for precise points in time. If the determining factors or input parameters of the workstation, such as capacity levels or lot sizes, change under real conditions, or if 


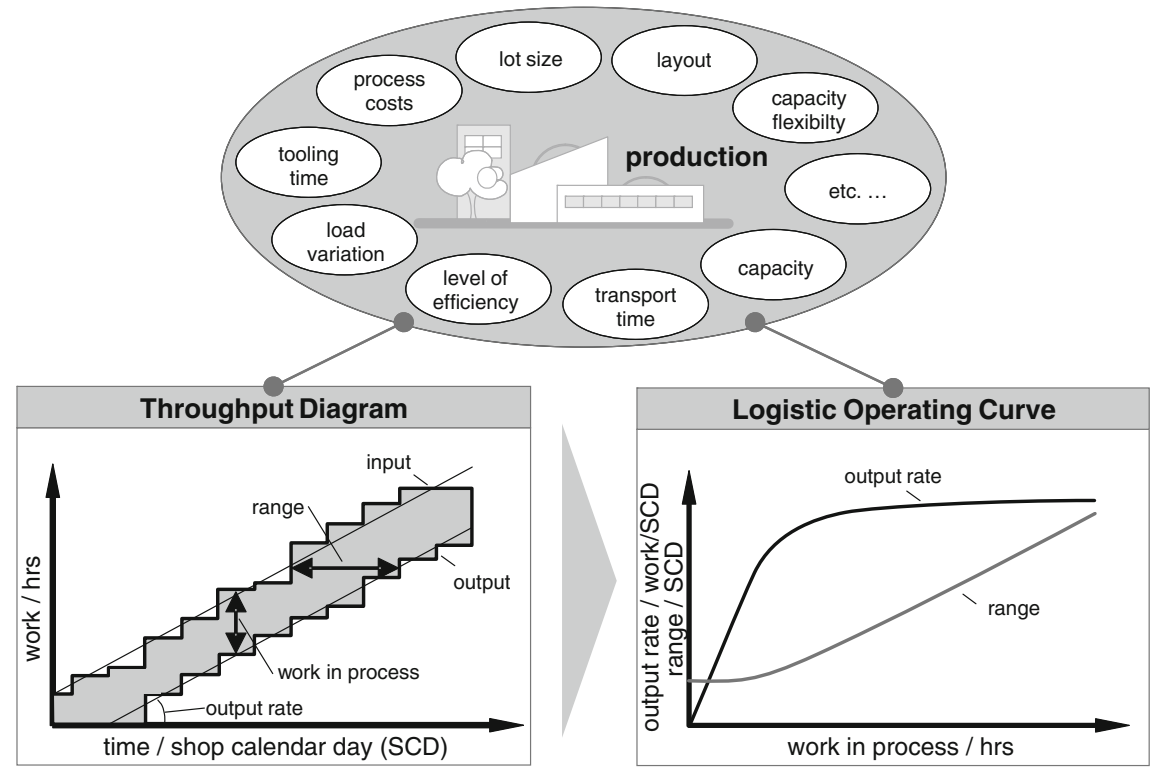

Fig. 3.3 Real factors determining the throughput diagram and logistic operating curves

there are any process disturbances, the effects can be calculated directly and quantitatively. However, the throughput diagram does not-or not fully-describe the cause-effect relationships between the logistic parameters. Hence, one central challenge encountered in deriving logistic operating curves was to determine the causeeffect relationships between the determining factors and the target variables taking into account all determining factors relevant to production. The ideal logistic operating curves were derived in an initial deductive modelling stage. This describes the theoretical limiting values of the logistic key performance indicators with the underlying cause-effect relationships. The modelling of the cause-effect relationships between the performance parameters in real process flows and disturbances was conducted by means of the experimental analysis of simulation results for the purpose of parametric adjustment. This process of deductive-experimental modelling enables the logistic operating curves to adapt easily to changes in framework conditions. Since both the model structure and the input parameters of the model primarily originate from elementary principles, the cause-effect relationships between the logistic target variables can be easily described (Nyhuis et al. 2009).

Figure 3.4 shows examples of further logistic models which, taken together and in the given combination, lead to the formulation of a production logistic theory. The scope of observation comprises the internal supply chain between the procurement and sales markets, which consists of idealised supply, assembly and sales processes. Numerous logistic models have been developed for the respective process elements store, manufacturing, assembly and distribution. Selected models are briefly presented in the following. 


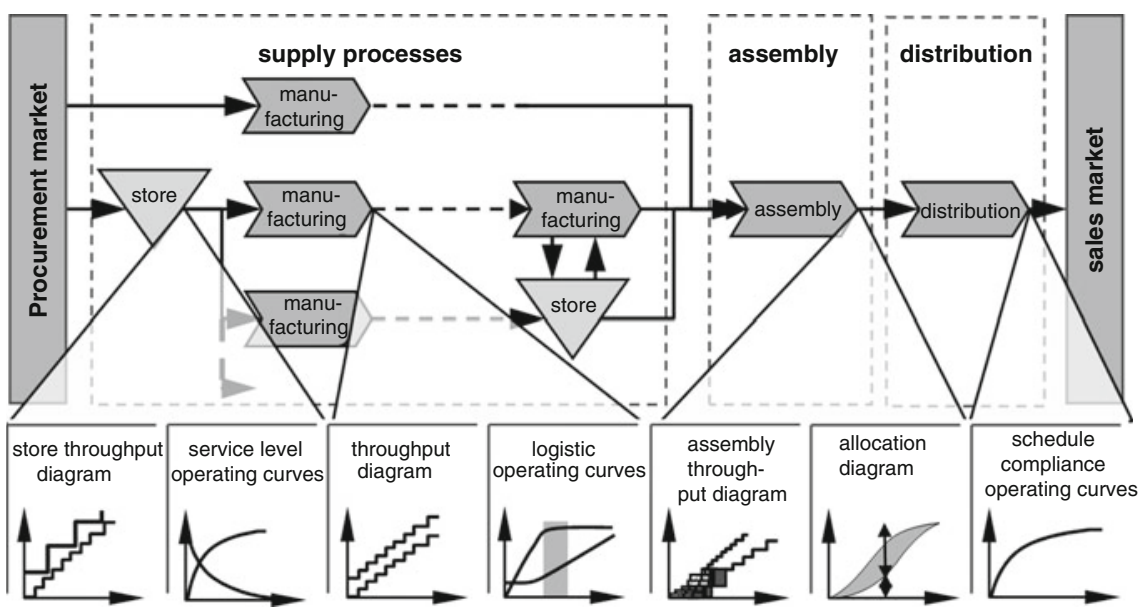

Fig. 3.4 Selected logistic models in the internal supply chain

Warehouse processes can be analysed at various distribution levels by means of the store throughput diagram (Gläßner 1995) and the service level operating curve (Lutz 2002). These models support to indicate service levels and existing potentials. Moreover, article-specific safety stock can be dimensioned.

As outlined above, manufacturing processes can be described qualitatively and for precise points in time by means of the throughput diagram. Building on this, the logistic operating curves show the functional dependencies between the logistic target variables output rate, throughput time, inter-operation time and range. The progression of these target variables is shown as a function of the work in process. This enables a controlling process for the logistic analysis and enhancement of existing production processes. The central challenge encountered in assembly processes lies in the logistic coordination of upstream processes, which can be analysed by means of the assembly throughput diagram (Münzberg et al. 2012; Schmidt 2011). The allocation diagram (Nyhuis et al. 2013; Beck 2013; Nickel 2008) supplies quantitative statements regarding the consequence of delayed supply from the upstream processes. Moreover, it enables potential to be identified in terms of inventory costs and delivery reliability with regard to assembly processes. Delivery reliability and schedule compliance are particularly important purchasing criteria with respect to the sales market. The schedule compliance operating curves (Schmidt et al. 2013) enable an analysis of the scheduling situation of external suppliers or customer-supplier relations within the company, and describe the interrelations between schedule adherence, safety time and stock.

It is now apparent that the logistic models have led to a consistent understanding of the system that constitutes the internal supply chain. This makes it possible to describe, predict and influence logistic system behaviour with respect to logistic parameters such as work in process or lateness. On the basis of these known causeeffect relationships, it is possible to implement a theoretically grounded means of 
supporting decision-making processes in companies. Models such as the determination of lot-size, safety stock or scheduling of production orders have proven to be of immense practical and sustainable benefit in industrial practice.

It must be borne in mind that the models presented here should be regarded as partial models. Further work is currently being conducted to develop link-variables between the models, by which it will be possible to connect the partial models to form a complete production logistic theory.

Provided the relevant research gaps in the scope of observation can be detected and closed in the near future, it will be possible to gradually expand it. It is therefore conceivable that the theory of production logistics might be extended to incorporate the external supply chain or other target fields such as ecology.

As already stated in the foregoing, the IFA has been involved in researching into a theory of production logistics for the past 40 years. A conspicuous aspect of this is that the development intervals that lead to the formulation of new models are becoming increasingly shorter. While the interval that lay between publications relating to the throughput diagram (Heinemeyer 1974) and those referring to the logistic operating curves (Nyhuis 1991) was as long as 17 years, just under three years separated the development of the assembly throughput diagram (Schmidt 2011) from the analytical description of the allocation diagram (Beck 2013). One of the main reasons for this is the increasing degree of understanding of theory and model development that prevails at the IFA, the effect of which is to considerably accelerate the development process. It is also apparent that the process of theory development not only requires experience but also endurance on the part of research institutes and sponsors of research.

The production logistic theory represents an integral part of production logistics. A comprehensive theory of production technology is necessary to allow comprehensive statements to be made and to recommend courses of action above and beyond the subdisciplines. Initial ideas and approaches will be presented in the following.

\subsection{Towards a Theory of Production Technology}

The overriding objective of production technology is to transform materials into goods that are destined for a sales market. As a technical science, production technology incorporates principles of natural, economic and social sciences as well as humanities (Spur 2006). Owing to the diverse issues involved, the interlinking of theory and practice plays a particularly important role.

For several decades, numerous approaches have been adopted in the field of business administration towards modelling production by means of a general theory. It is hence impossible within this framework to present a comprehensive overview of the state of the art. Reference is therefore made to Dyckhoff (2002) who recently published an excellent overview along with an appeal that production theory should undergo continued development. He defines production as value 
Fig. 3.5 Basic model of a general production theory in business administration (acc. to Dyckhoff (2006))

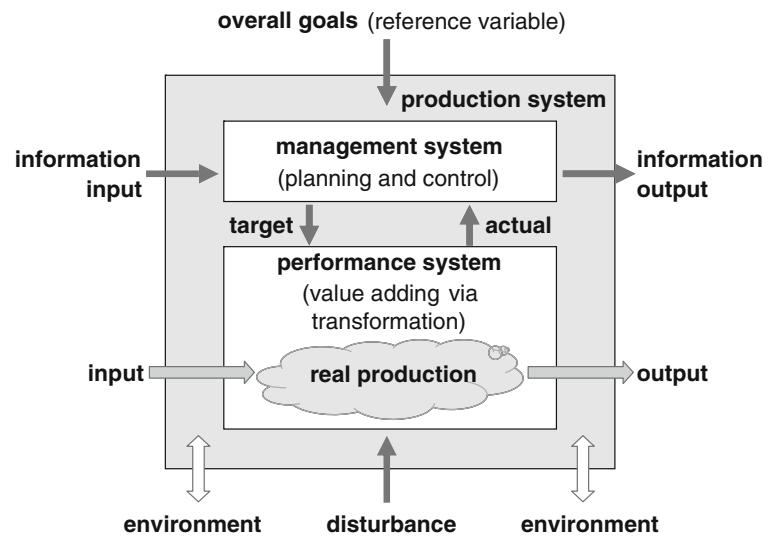

creation that comes about by means of transformation. A transformation is characterised by a qualitative, quantitative, spatial or temporal change of an object or its properties. The basic structure of the general theory of production is illustrated in Fig. 3.5 (Dyckhoff 2006).

A production system consists of two subsystems, the performance system and the management system, which are in a state of interaction with the environment. The performance system comprises the value adding transformation, which is planned, controlled and monitored by the management system. The object under analysis in the general theory of production is the relationship between input and output, which itself can be affected by external disturbance factors. These interrelations are in general formally described by means of production functions. Reference variables are derived from the overall economic goals; these have an effect on the management system. The management system develops targets for the production programme on the basis of incoming information from the market and environment. This is passed on to the performance system, which generates an output from the input variables by means of various transformation processes, in the form of products for the sales market. The actual is reported back to the management system.

A major weakness of the basic model of a general production theory in business administration lies in the functions of production, as these do not explicitly take into account the real value-creation processes. It is not possible to draw direct conclusions about the output of the performance system as a whole from a change brought about to a single production factor, for example the manpower at a workstation. In particular variant rich piece-wise productions of multi-staged products are not practically described by such production functions. Rather, technologically founded transformation steps with varied interaction levels must be taken into consideration. As a rule, resources in the form of raw materials, semi-manufactures and purchased parts are transformed into goods and products in the course of several production and assembly stages. This also requires operative control of production processes, plants and machinery. The scope of production under observation should therefore 
be expanded to include operative planning and control on the one hand and technological and logistic transformation processes on the other. Furthermore, there are numerous overall goals beside cost-effectiveness to be pursued by businesses in order for them to remain sustainably successful. Logistic performance criteria such as delivery time and delivery reliability must be taken into consideration, as must such factors as flexibility or transformability in the face of short-notice changes to customer requirements. Moreover, ecological and social aspects are becoming increasingly important factors when it comes to fulfilling the overall goal of sustainable production (Nyhuis and Wiendahl 2010; Wiendahl et al. 2010).

The German Academic Society for Production Engineering (WGP) has taken on the task of taking the aforementioned criticisms on board and additionally incorporating a technological production model in the basic model of a general production theory in business administration. Figure 3.6 shows a schematic diagram of this extension.

The technological production model still consists of a management system and a performance system. The overall goal of sustainability has now been incorporated, and alongside economic, ecological and social aspects, functional compliance of the manufactured products has been added. This ensures that production is incorporated as a factor in the fulfilment of customer requirements. The input variables are information, work-force, materials and energy; these are transformed by means of the performance system into elements, parts, part families or sub-products, products

overall goal of production: market conform products generated by a sustainable production

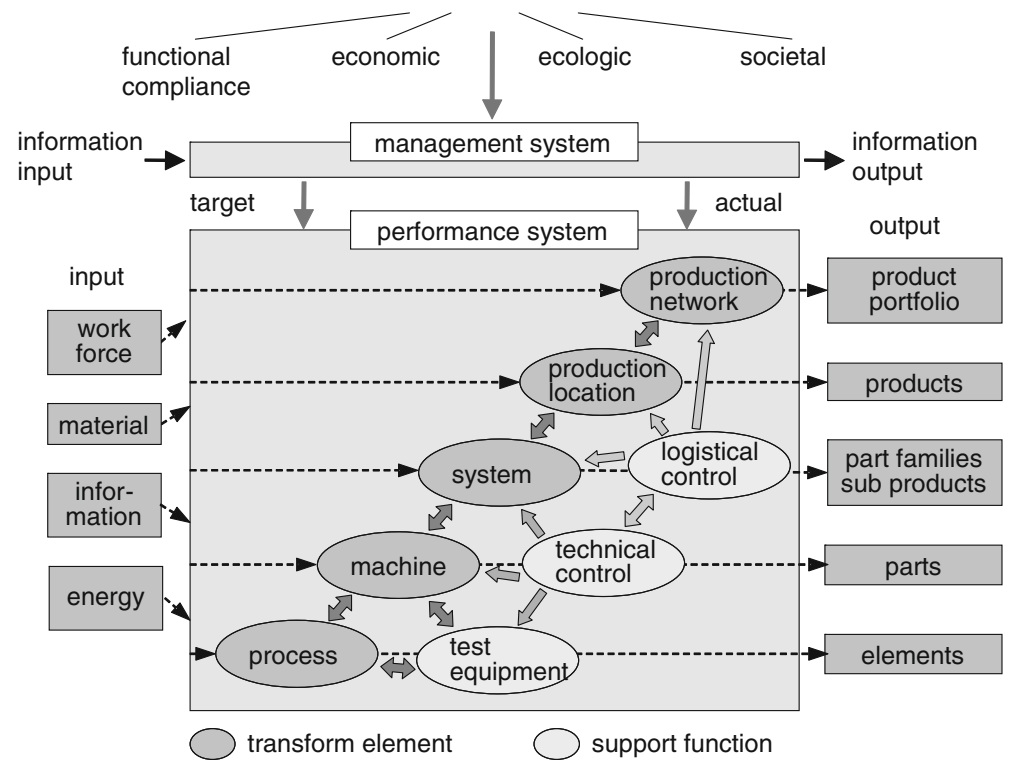

Fig. 3.6 Extension of the basic model of a general production theory in business administration 
and overall into a product portfolio. Within the performance system there are transform elements: process, machine, system, production location and production network, to which the support functions of test and measuring equipment, technical control and logistic control have been added.

In order to develop a theory of production technology, it is necessary to determine submodels within and between the transform elements and to derive hypotheses from these. An important first step consists of further subdividing the overall goals. For example, of relevance to functional compliance on the level of elements and parts are the features for denoting the geometric body, its surface, its material properties and its service life. On the product level, the main aspects are functionality, performance and appearance. As for the economic goals, of primary interest are cycle times, tooling times, throughput times and manufacturing costs; delivery times, delivery compliance and the effect on turnover have been added on the upper levels. The ecological goals are characterised by both the material aspect (material utilisation, reutilisation) and the energy aspect; the environmental pollution generated by the production facilities has now been added. Finally, social goals are oriented towards the immediate workplace location and primarily concern their ergonomic and safe design. Of decisive importance at higher levels are such factors as personal communication, and the work content determined by the structural organisation, as well as trust and cooperation (Nyhuis and Wiendahl 2010; Wiendahl et al. 2010).

The WGP model presented here represents a generally valid approach to a theory of production technology. It involves a highly interconnected performance system on various production aggregation levels. Once the individual subdisciplines of production technology have been modelled, it will be possible to consistently describe, predict and influence the behaviour of the transform and support elements. This knowledge of the complex interactions will lead to the implementation of a consistently designed and efficiently coordinated system. This will allow companies to ensure sustainable production and enhance company success even in times of turbulence.

\subsection{Summary and Outlook}

Companies today must meet the challenge of asserting themselves within a nondeterministic and turbulent environment. For this reason, a theoretical understanding of production is absolutely vital so that predictions may be made and courses of action recommended within this state of increasing complexity. The development of a production logistic theory at the IFA clearly shows the scientific and practical benefits of such generally valid theories. Once developed, such logistic models will make it possible to determine the interactions taking place within the internal supply chain in a manner that is both inexpensive and theoretically grounded and thus to support commercial decision-making processes. Furthermore, it has been shown that a theory development process requires much in the way of both experience and 
endurance on the part of research institutes and sponsors. Although theoretical approaches relating to production already exist, they are not in themselves sufficient for explaining the complex interactions that take place within production. Accordingly, the scientific and theoretical understanding of production technology as a whole constitutes a major research gap. The WGP approach to a theory of production technology presented here represents an attempt to close this gap by substantiating the scope of observation by means of the technological production model. The aim is to orient the entire performance system with its complex interactions, taking into account the defined overall goals. To this end, further efforts will be required in all subdisciplines to derive research questions from the substantiated overall goals and to develop the respective models. Following this, the individual integral models and theories can be merged to form a theory of production technology.

Open Access This chapter is distributed under the terms of the Creative Commons Attribution Noncommercial License, which permits any noncommercial use, distribution, and reproduction in any medium, provided the original author(s) and source are credited.

\section{References}

Abele E, Reinhart G (2011) Zukunft der Produktion. Herausforderungen, Forschungsfelder, Chancen. Hanser Verlag, München

Beck S (2013) Modellgestütztes Logistikcontrolling konvergierender Materialflüsse. Berichte aus dem IFA, vol 2013,3. PZH Produktionstechnisches Zentrum, Garbsen

BMU (ed) (2012) GreenTech made in Germany 3.0. Umwelttechnologie-Atlas für Deutschland, Bundesministerium für Umwelt, Naturschutz und Reaktorsicherheit, Berlin

Deutsche Post AG (ed) (2010) Delivering Tomorrow. Towards Sustainable Logistics, Deutsche Post AG, Bonn

Dyckhoff H (2002) Neukonzeption der Produktionstechnologie. ZfB - Zeitschrift für Betriebswirtschaft 73(Heft 3):705-732

Dyckhoff H (2006) Produktionstheorie. Grundzüge industrieller Produktionswirtschaft, 5. überarbeitete Aufl. Springer, Berlin, New York

Gläßner J (1995) Modellgestütztes Controlling der beschaffungslogistischen Prozesskette, Als Ms. gedr., vol 337. VDI Verlag, Düsseldorf

Heinemeyer W (1974) Die Analyse der Fertigungsdurchlaufzeit im Industriebetrieb. Offsetdruck Böttger, Hannover

Kettner H, Bechte W (1976) Neue Wege der Bestandsanalyse im Fertigungsbereich. Methodik, praktische Beispiele, EDV-Programmsystem. Fachbericht des Arbeitsausschusses Fertigungswirtschaft (AFW) der Deutschen Gesellschaft für Betriebswirtschaft (DGfB). Inst. für Fabrikanalgen (IFA) der Techn. Univ, Hannover

Lödding H (2013) Handbook of Manufacturing Control. Fundamentals, description, configuration. Springer, Berlin, Heidelberg

Lutz S (2002) Kennliniengestütztes Lagermanagement. Univ., Diss.-Hannover, 2002, Als Ms. gedr. Reihe 13, Fördertechnik/Logistik, vol 53. VDI-Verl, Düsseldorf

Münzberg B, Schmidt M, Beck S, Nyhuis P (2012) Model based logistic monitoring for supply and assembly processes. Prod. Eng. Res. Devel. 6(4-5):449-458. doi: 10.1007/s11740-0120403-9

Nickel R (2008) Logistische Modelle für die Montage. Berichte aus dem IFA, 2008, Bd. 02. PZH, Produktionstechn. Zentrum, Garbsen 
Nyhuis P (1991) Durchlauforientierte Losgrößenbestimmung, Als Ms. gedr., Nr. 225. VDI Verlag; Düsseldorf

Nyhuis P, Beck S, Schmidt M (2013) Model-based logistic controlling of converging material flows. CIRP Annals - Manufacturing Technology 62(1):431-434. doi: 10.1016/j.cirp.2013.03. 041

Nyhuis P, Wiendahl HP, Rossi R (2009) Fundamentals of production logistics. Theory, tools and applications; with 6 tables. Springer, Berlin

Nyhuis P (2007) Practical Applications of Logistic Operating Curves. CIRP Annals Manufacturing Technology 56(1):483-486. doi: 10.1016/j.cirp.2007.05.115

Nyhuis P, Wiendahl H P (2010) Ansatz zu einer Theorie der Produktionstechnik. Zeitschrift für wirtschaftlichen Fabrikbetrieb 105(1-2):15-20

Nyhuis P, Wiendahl H P (2007) Ansätze einer Logistiktheorie In: Hausladen I (ed) Management an Puls der Zeit-Strategien, Konzepte und Methoden, 1. Aufl. TCW Transfer-Centrum, München

Popper K (1935) Logik der Forschung. Springer Vienna, Vienna

Roland Berger Strategy Consultants GmbH (2012) Mastering product complexity. http://www. rolandberger.us/media/pdf/Roland_Berger_Mastering-Product-Complexity_20121107.pdf. Accessed 25 Aug 2014

Schmidt M (2011) Modellierung logistischer Prozesse der Montage. Univ., Diss.-Hannover, 2010. Berichte aus dem IFA, vol 2011,1. PZH Produktionstechn. Zentrum, Garbsen

Schmidt M, Bertsch S, Nyhuis P (2013) Schedule compliance operating curves and their application in designing the supply chain of a metal producer. Production Planning \& Control:1-11. doi: 10.1080/09537287.2013.782947

Sirkin H, Bradtke T, Lebreton J, Young D (2004) What is globalization doing to your business. https://www.bcgperspectives.com/content/articles/globalization_operations_what_is_globaliza tion_doing_to_your_business/

Spur G (2006) Erscheinungsformen und Modelle technischer Systeme: Ein Beitrag zur theoretischen Begründung der Technikwissenschaften. Parthey, H.; Spur, G.(Hg.): Wissenschaft und Technik in theoretischer Reflexion. Jahrbuch Wissenschaftsforschung:103-130

National Academy of Sciences (1998) Teaching evolution and the nature of science. National Academy Press, Washington, D.C.

Weber J (2008) Überlegungen zu einer theoretischen Fundierung der Logistik in der Betriebswirtschaftslehre. In: Nyhuis P (ed) Beiträge zu einer Theorie der Logistik. SpringerVerlag, Berlin, Heidelberg, pp 43-65

Wiendahl H P (1987) Belastungsorientierte Fertigungssteuerung. Grundlagen, Verfahrensaufbau, Realisierung; 36 Tabellen. Hanser, München

Wiendahl H P, Nyhuis P, Hartmann W (2010) Should CIRP develop a Production Theory? Motivation, Development Path, Framework, 43rd International Conference on Manufacturing Systems, Vienna, 26.-28.05.2010, pp. 3-18 